João Pessoa, v. 7, n. 1, p. 20-38, jan./abr. 2019. ISSN 2318-1001

DOI: $10.22478 /$ ufpb.2318-1001.\%Yv\%vn\%i.36118

Disponível em: http://periodicos.ufpb.br/ojs2/index.php/recfin

\title{
DIFICULDADES DO DOCENTE NO PROCESSO DE ORIENTAÇÃO EM TRABALHOS DE CONCLUSÃO DE CURSO: UM ESTUDO EM CURSOS DE CIÊNCIAS CONTÁBEIS EM INTI- TUIÇÕES DE ENSINO SUPERIOR DA GRANDE RECIFE ${ }^{1}$
}

\section{PROFESSOR'S DIFFICULTIES IN THE ORIENTATION PROCESS OF END OF COURSE WORK: A STUDY IN ACCOUNTING COURSES IN A HIGHER EDUCATION INSTITUTION OF RECIFE}

\author{
Alexsandra Guedes da Silva ${ }^{2}$ \\ Graduada em Ciências Contábeis - Faculdade Santa Helena (FSH) \\ aleguedess87@hotmail.com \\ Fabiana Minhaqui Santos Guerra de Morais \\ Graduada em Ciências Contábeis - Faculdade Santa Helena (FSH) \\ faminhaqui@gmail.com \\ Ivana Porto Farias \\ Graduada em Ciências Contábeis - Faculdade Santa Helena (FSH) \\ ivanapf@hotmail.com \\ Priscilla Milfont de Medeiros \\ Mestre em Ciências Contábeis - Universidade Federal de Pernambuco (UFPE) \\ priscillamilfont@gmail.com \\ João Gabriel Nascimento de Araújo \\ Mestre em Ciências Contábeis - Universidade Federal de Pernambuco (UFPE) \\ jgabrie190@hotmail.com
}

\begin{abstract}
RESUMO
Objetivo: O presente estudo tem como objetivo geral identificar as dificuldades do processo de orientação em TCC's, sob a percepção dos docentes de Ciências Contábeis de Instituições de Ensino Superior da grande Recife.

Fundamento: O TCC exige do aluno uma maior clareza e entendimento para desenvolver as suas produções científicas, porém alguns desses aspectos podem dificultar a elaboração das pesquisas, e
\end{abstract}

\footnotetext{
${ }^{2}$ Artigo recebido em: 28/02/2018. Revisado por pares em: 10/04/2018. Reformulado em: 026/06/2018. Recomendado para publicação, após a segunda rodada, em: 26/06/2018 por Adriana F. de Vasconcelos (Editora Adjunta). Publicado em: 25/01/2019. Organização responsável pelo periódico: UFPB

${ }^{2}$ Endereço: Av. Caxangá, n. 990, Madalena - Recife/PE - 50711-000
} 
muitas delas podem ser percebidas por parte dos professores que acompanham diretamente a construção do trabalho científico durante o processo de orientação (Medeiros, Rocha, Silva \& Danjour, 2015). O docente tem papel chave para auxiliar o estudante a atingir seu objetivo na conclusão de seu trabalho final, coordenando o aluno de maneira que este consiga demonstrar conhecimento tanto da literatura existente sobre o tema escolhido, como na organização sistemática do trabalho (Brizolla, Basso \& Soschinski, 2014).

Método: Como instrumento para coleta de dados da pesquisa foi aplicado um questionário a 31 docentes do curso de Ciências Contábeis de instituições de ensino superior de Pernambuco. O questionário foi estruturado em quatro blocos, e contemplou a análise do perfil do docente, o aspecto cognitivo (conhecimento em metodologia), o aspecto operacional (planejamento de pesquisa) e o aspecto relacional (relação aluno-professor). O questionário teve sua consistência interna testada através do Alfa de Cronbach.

Resultados: Sobre as dificuldades encontradas em relação ao aspecto cognitivo, observou-se que a maioria dos docentes apresentou muitas orientações durante os últimos dois semestres. No aspecto operacional a dificuldade que os orientadores possuem é na redação dos seus orientandos nos trabalhos, bem como a falta de assimilar e seguir a metodologia, o cronograma, o conhecimento das normas e as formas como as referências devem ser citadas, a lógica que deve seguir, a maneira como os resultados devem ser apresentados, por fim, a importância da correlação entre o tema, problema, objetivos, método e a conclusão. Em relação ao aspecto relacional, as opções de "interesse e dedicação", "comunicação" e "cooperação" foram as únicas que apresentaram a resposta que os orientandos atendem a poucas expectativas.

Contribuições: Esta pesquisa revelou a necessidade de expor os problemas que ocorrem durante as orientações das pesquisas acadêmicas através da visão do docente, para que se possa evitar um baixo desempenho dos envolvidos no processo durante a elaboração do TCC. Com isso, toma-se como sugestão a realização de ações e projetos nas IES no intuito de desenvolver o conhecimento dos alunos de como elaborar um trabalho científico.

Palavras-chave: Trabalho de conclusão de curso. Orientação. Docentes. Ciências Contábeis

\section{ABSTRACT}

Objective: This paper aims to identify the orientation process' difficulties in undergraduate thesis, under accounting professor's perception of Higher Education Institutions in Recife.

Rationale: The undergraduate thesis demands from the student a greater clarity and understanding to develop their productions, but some of these aspects may hinder the elaboration of the researches, and many of them can be perceived by the professors who follow directly the construction of the scientific work during the orientation process (Medeiros, Rocha, Silva \& Danjour, 2015). The professors have a very important role to help the student achieve his goal in the conclusion of his final work, the teacher coordinates the student so that he can demonstrate knowledge of both the existing literature on the chosen theme and in the systematic organization (Brizolla, Basso \& Soschinski, 2014).

Method: As a tool for collecting research data, a survey was applied with 31 accounting professors' of higher education institutions in Pernambuco. The survey was structured in four blocks that included the analysis of the professor's profile, the cognitive aspect (knowledge in methodology), the operational aspect (research planning) and the relational aspect (student-teacher relationship). The survey had its internal consistency tested through Cronbach's Alpha.

Results: Regarding the difficulties found in relation to the cognitive aspect, it was observed that most professors presented many orientations during the last two semesters. In the operational aspect, the difficulty that the guiding teachers have is in the writing of their students in the works, as well as the lack of assimilation and follow the methodology, the schedule, the knowledge of the 
norms and forms as the references must be quoted, the logic that must follow, the way the results should be presented, and finally, the importance of the correlation between the theme, the problem, the objectives, the method and the conclusion. Regarding the relational aspect, the options of "interest and dedication", "communication" and "cooperation" were the only ones that presented the answer that the respondents met with few expectations.

Contributions: This paper has revealed the need to expose the problems that occur during academic research orientations through the professor's view so that you can avoid poor performance by those involved in the process during the undergraduate thesis development process. Hence, it is suggested as the accomplishment of actions and projects in the higher education institutions in order to develop students' knowledge through practices of how to elaborate a scientific work.

Keywords: Undergraduate Thesis. Orientation. Professors. Accounting.

\section{INTRODUÇÃO}

Desde a promulgação da Lei de Diretrizes e Base da Educação Nacional (Lei n. 9.394, 1996), muitas mudanças ocorreram no sistema de ensino do país. Essas mudanças trouxeram consigo a necessidade das Instituições de Ensino Superior (IES) se aprimorarem para atender às demandas do mercado de trabalho. Como forma de responder a essa demanda, as IES precisam transmitir conhecimento através de atividades de ensino, pesquisa e extensão (Alencar, 2016).

Uma das formas encontradas, mesclando ensino e pesquisa, foram os trabalhos de pesquisa de conclusão de curso e monografia que são atividades obrigatórias nas universidades e faculdades para os alunos obterem grau e, consequentemente, desenvolverem o conhecimento em qualquer área de atuação.

Essa abordagem para finalizar a graduação pode ser vista como positiva para construção do conhecimento do aluno, como aponta Pessoa Junior e Lima (2015) ao dizerem que o trabalho de conclusão de curso (TCC) consegue estabelecer uma conexão entre aspectos da pesquisa e do ensino, sendo mais um método a auxiliar na aprendizagem do estudante, e no trabalho do professor, possibilitando o estímulo a pesquisa e ao ensino.

O TCC, como ferramenta de incentivo a pesquisa e ao ensino, é um trabalho desenvolvido sobre um tema relacionado com a formação, tendo como finalidade a conclusão do curso, e pode ser considerado um trabalho de iniciação científica, já que para seu desenvolvimento empregam-se processos e métodos próprios da ciência (Müller \& Cornelsen, 2003).

Em outras palavras, Silva, Sihler e Silva (2012) salientam que o processo de elaboração de um estudo no final da graduação é percebido como um momento que se sistematiza a aprendizagem desenvolvida durante o período do curso, sendo marcado pela criação, organização e registro de ideias as quais geram as pesquisas com base no conhecimento construído.

Desta forma, as pesquisas nos cursos superiores são importantes para o desenvolvimento do conhecimento em qualquer área de atuação. No curso de Ciências Contábeis não é diferente, e os estudos são realizados abordando problemáticas que visam à produção de conhecimento e aprimoramento das práticas profissionais.

O TCC exige do aluno uma maior clareza e entendimento para desenvolver as suas produções, porém alguns desses aspectos podem dificultar a elaboração das pesquisas, e muitas destas dificuldades podem ser percebidas por parte dos professores que acompanham diretamente a construção do trabalho científico durante o processo de orientação (Medeiros, Rocha, Silva \& Danjour, 2015).

Algumas destas dificuldades para inserção no mundo da pesquisa foram identificadas no estudo desenvolvido por Krüger, Valmorbida, Ensslin, Ensslin e Vicente (2013), os quais verificaram que durante a graduação de 262 estudantes pesquisados, apenas 225 tinham lido no mínimo um artigo científico, e estes apontam que leram por ser exigência de uma disciplina, 120 haviam escrito 
ao menos um artigo e somente 40 deram andamento aos seus trabalhos e os publicaram. Dentre as alegações para a leitura e produção de trabalhos científicos, os alunos apontaram a dificuldade para conseguir realizar a coleta dos dados necessários para realizar o estudo, assim como a falta de tempo.

Com papel chave para auxiliar o estudante a atingir seu objetivo na conclusão de seu trabalho final está o docente orientador, o qual coordena o aluno de maneira que este consiga demonstrar conhecimento tanto da literatura existente sobre o tema escolhido, como na organização sistemática do trabalho (Brizolla, Basso \& Soschinski, 2014).

Diante do objetivo do trabalho de conclusão de curso e das dificuldades apresentadas pelos discentes para realização do mesmo, a questão norteadora do estudo foi: Quais as dificuldades do processo de orientação em TCC's, sob a percepção dos docentes de Ciências Contábeis de Instituições de Ensino Superior da grande Recife?

Em consonância com a questão de pesquisa, o objetivo geral do estudo foi identificar as dificuldades do processo de orientação em TCC's, sob a percepção dos docentes de Ciências Contábeis de Instituições de Ensino Superior da grande Recife. Como objetivos específicos têm-se: analisar o perfil dos docentes, verificar o comprometimento dos alunos na elaboração dos TCC's e avaliar a relação professor-aluno.

Alguns trabalhos, em diversas áreas como contabilidade, pedagogia e enfermagem, já foram desenvolvidos e buscaram identificar e entender à percepção dos discentes sobre as dificuldades no processo de elaboração do TCC, tais como os de Dias (2011), Campos, Santos \& Santos (2009), Santos (2011). Entretanto, o papel do orientador, conforme apresentado nesta introdução, é ponto chave para que o estudante consiga desenvolver seu trabalho de maneira mais ordenada e fácil. Diante deste aspecto, poucos trabalhos em contabilidade focando nas dificuldades que o orientador enfrenta no processo de orientação foram encontrados, cabendo destaque o estudo de Alencar (2016). Por isso, este estudo encontra sua justificativa e contribuição ao buscar demonstrar as dificuldades no processo de orientação dos trabalhos de conclusão de curso sob a percepção dos professores orientadores, com o objetivo de que novas formas de abordagem no processo de orientação possam ser desenvolvidas a partir dos problemas identificados.

A pesquisa está estruturada em cinco partes. Além desta introdução, há a revisão da literatura, com tópicos sobre a importância da pesquisa científica nas IES, o trabalho de conclusão de curso, o processo de pesquisa para a elaboração de TCC's e estudos anteriores sobre o tema. A terceira parte apresenta a metodologia, especificando o tipo de pesquisa e os métodos que foram utilizados para o desenvolvimento da pesquisa. A quarta etapa registra os resultados dos estudos com as análises realizadas a partir dos dados obtidos. Por fim, a conclusão, onde constam as considerações finais do trabalho.

\section{REVISÃO DA LITERATURA}

\subsection{O Trabalho de Conclusão de Curso}

As pesquisas são realizadas de várias formas na graduação, por meio de projetos de iniciação científica, pesquisas científicas sob a orientação de professores de determinadas disciplinas, bem como pelo trabalho de conclusão de curso vinculado à obtenção do título dos graduandos (Almeida \& Leal, 2015).

O Trabalho de Conclusão de Curso é uma forma de pesquisa acadêmica utilizada no ensino superior como uma maneira de realizar a avaliação final dos graduandos e pós-graduandos, podendo ser entregue na forma de monografia, projeto, artigo, entre outros, e, geralmente, contém a defesa pública do trabalho perante uma banca examinadora.

A Associação Brasileira de Normas Técnicas, através da NBR 14724 (ABNT, 2011), menciona que o TCC é a representação documental do resultado que foi obtido através do desenvolvimento 
de um estudo, o qual deve expressar conhecimento sobre o tema optado, sendo este derivado de alguma disciplina do curso ou programa, devendo ser feito sob a supervisão de um orientador.

A Resolução do Conselho Nacional de Educação/Câmara de Educação Superior - CNE/CES n.. 10/2004, que instituiu as Diretrizes Curriculares Nacionais para o Curso de Graduação em Ciências Contábeis, Bacharelado, a serem observadas pelas Instituições de Ensino Superior, destaca em seu artigo 9a que o trabalho final de curso pode ser adotado como opcional pelas instituições de ensino superior, mas quem optar por utilizá-lo, poderá colocar à disposição dos estudantes modalidades para desenvolver o TCC, como a monografia, o projeto de iniciação científica ou projetos de atividades focados em áreas teórico-práticas e de formação profissional associadas ao curso.

A Resolução CNE/CES n.. 10/2004 ressalta, ainda, que a Instituição, optando por incluir TCC, deverá emitir regulamentação própria, aprovada pelo seu Conselho Superior Acadêmico, incluindo critérios, procedimentos e mecanismos de avaliação, além das diretrizes técnicas relacionadas à sua elaboração.

O TCC possibilita a expansão dos conhecimentos já adquiridos pelo aluno durante o curso e também pode ser entendido como um processo de Iniciação Científica, o qual se configura como um instrumento metodológico na busca de significados, proporcionando a construção de novos saberes (Peixoto et al., 2014). Tal atividade passa a ser um mecanismo substancial para a consolidação das competências adquiridas durante o curso e configura-se como uma conquista de capacidades para realizar o trabalho de conclusão (Neves \& Russi, 2007).

As monografias e TCC's são escritas sobre um tema que não precisa ser absolutamente inédito, mas deve satisfazer às exigências e especificações do curso e fazem parte do processo didático. No entanto, não existem restrições de que se abordem relações com outros temas e de que se adotem vários aspectos de um mesmo tema (Diehl, 2004).

Os estudos que abordam pesquisas científicas durante a graduação em Ciências Contábeis no Brasil são recentes, porém tem sido mais frequente nos últimos anos, sendo encontrados, de maneira geral, através de métodos estatísticos e matemáticos, com avaliação quantitativa de artigos, relatórios científicos, entre outros (Theóphilo \& Iudícibus, 2009).

Carneiro (2009), sobre o art. $3^{\mathrm{o}}$ da Proposta Nacional de Conteúdo para o curso de graduação em Ciências Contábeis, editado pelo Conselho Federal de Contabilidade (CFC), esclarece os objetivos gerais do trabalho de conclusão de curso e o propósito do TCC, que são: possibilitar ao aluno o desenvolvimento intelectual, habilidades e atitudes necessárias à profissão; fornecer meios para que exista a integração entre os conhecimentos que foram angariados durante o decorrer do curso; e favorecer o desenvolvimento do pensamento crítico.

O interesse das universidades e faculdades que possuem o curso de Ciências Contábeis vem crescendo em relação a oferecer e favorecer as oportunidades no desenvolvimento do processo de pesquisas científicas através de seus pesquisadores, professores e estudantes, tendo como objetivo buscar analisar os fenômenos que ocorrem na área contábil e, com isso, contribuir no avanço desses estudos nos últimos anos (Silva; Oliveira \& Ribeiro Filho, 2005; Brunozi Júnior; Emmendoerfer; Abrantes \& Klein, 2011).

O TCC proporciona uma maior interação entre o orientador e seu orientando, facilitando o desenvolvimento de pesquisas na graduação. Nesse sentido, a iniciação científica impulsiona nos alunos dos cursos de Ciências Contábeis o aprimoramento e conhecimento, através das orientações, a terem interesse em realizar pesquisas e influenciá-los na formação e desempenho de suas habilidades e competências, bem como disseminar a pesquisa científica (Santos \& Leal, 2014).

\subsection{Processos de Pesquisa para Elaboração de TCC's}


O Trabalho de Conclusão de Curso está presente como componente curricular obrigatório nas Instituições de Ensino Superior, onde conta com o apoio de um professor da própria instituição como orientador.

O orientador atua, essencialmente, como um ponto de apoio, uma pessoa a quem o estudante pode recorrer para discutir suas preocupações com o conteúdo abordado em sua pesquisa, com a metodologia adotada na condução da mesma e, também, estabelecer uma relação de parceria com os discentes, atuar como guia, provocador do conhecimento, e coautor, mantendo a convivência e boa participação com os alunos, permitindo maior segurança e tranquilidade diante da incerteza no desenvolvimento de uma pesquisa cientifica (Quixadá-Viana \& Veiga, 2007).

A relação pedagógica na orientação acadêmica trata-se de um elo que, apesar de preservar particularidades gerais, por ser dinâmica e envolver pessoas, cada uma conta com suas subjetividades e se estabelece em níveis diferenciados entre o orientador e o orientado (Quixadá-Viana \& Veiga, 2010).

A função do orientador, segundo Severino (2009) deveria ser aquela de um educador, cuja experiência, mais amadurecida, ele compartilha com o orientando, num processo conjunto de construção de conhecimento. Esse autor relata que ambos interagem em um processo de acordos ou consenso, existindo um respeito em relação à autonomia e a personalidade de cada um. Dessa maneira, o orientador tem o papel de educador, que estabelece uma relação educativa com seu orientando para a elaboração de um o trabalho científico.

Medeiros, Silva \& Novais (2011), mencionam que o processo de pesquisa para elaboração de TCC's possui três dimensões essenciais para sua realização: o conhecimento em metodologia (aspecto cognitivo), o planejamento de pesquisa (aspecto operacional) e a condução da orientação (aspecto relacional). Tais aspectos devem ser trabalhados de forma integrada e interdependente para construção e sucesso da pesquisa.

\subsubsection{Aspecto Cognitivo}

O aspecto cognitivo está associado às competências, conhecimentos e compreensão que o profissional do ensino tem sobre os aspectos metodológicos que dizem respeito ao seu trabalho (Medeiros; Silva \& Novais, 2011). Esses autores relatam que existem vários fatores que determinam ou servem como parâmetros para medir o nível de competência do profissional de ensino e um deles é o grau acadêmico, pois quanto maior for o nível de graduação, maior será a exigência de conhecimentos que esse profissional deve ter, bem como uma maior suposição de melhor visão acadêmica.

Segundo Boso, Garcia, Rodrigues \& Marcondes (2010), Piaget defendeu por diversas vezes que a cognição humana é uma forma de adaptação biológica na qual o conhecimento é construído aos poucos, a partir do desenvolvimento das estruturas cognitivas que se organizam de acordo com os estágios de desenvolvimento da inteligência. Assim, o desenvolvimento cognitivo acompanha o crescimento dos seres humanos ao longo de sua vida, variando e mudando de acordo com a idade.

Nesse sentido, quando se fala nos aspectos cognitivos do professor/orientador, espera-se que esteja familiarizado e desenvolvido durante a carreira acadêmica (nível de graduação, especialização, mestrado ou doutorado) o conhecimento, habilidade técnica e compreensão das áreas que atua, para que tenha um domínio da literatura dos temas que serão pesquisados.

Além disso, a atuação profissional de ensino é importante em atividades de pesquisa e extensão, bem como participação em orientações de TCC's, pois são atividades que requerem um maior conhecimento metodológico.

Bianchetti (2006) mostra que o nível acadêmico é importante para a atuação profissional na atividade de orientação, mas nem sempre é determinante, pois para ser um bom orientador, por 
exemplo, existe uma tendência a ser pensada que é preciso ter passado por um doutorado e praticado pesquisa. Contudo, pode-se ter o título sem praticar investigação, e pode-se ter o título exercendo a atividade de pesquisa.

\subsubsection{Aspecto Operacional}

O processo de elaboração de uma monografia ou TCC exige um planejamento cuidadoso. De modo geral, esse processo engloba a definição do tema, revisão da literatura, construção do préprojeto com a preparação da versão inicial da introdução, problema da pesquisa, a sua justificativa, o objetivo e o plano de assuntos, em seguida a realização do projeto, desenvolvimento da pesquisa seguindo a metodologia, a redação e a defesa (Dias \&Silva, 2009). Porém, no decorrer do estudo, podem ser encontradas dificuldades para cumprir as exigências do TCC. Muitos deles não conhecem as normas fundamentais para a produção de um texto científico, tais como: desenvolvimento e estrutura do trabalho (Pré-projeto), padrões de redação, procedimentos para realizar pesquisas bibliográficas, escolha e organização da leitura das obras, estruturação de citações diretas e indiretas, com a finalidade de incluí-las no corpo do próprio texto. Esses obstáculos podem ser a causa de grandes aflições para estes alunos, que inúmeras vezes podem levá-los ao desânimo e, até mesmo, o abandono do curso (Liston \& Silva, 2012).

Dias e Silva (2009), revelam que todo trabalho científico segue um ciclo iniciado pela observação do fenômeno que o pesquisador pretende estudar. Nesse sentido, é percebida a necessidade de seguir um planejamento para elaboração da pesquisa. Então, baseado na ideia desses autores, a Figura 1 apresenta um ciclo onde mostra como pode ser direcionada a realização de uma monografia.

Figura 1- Ciclo de Planejamento da Pesquisa

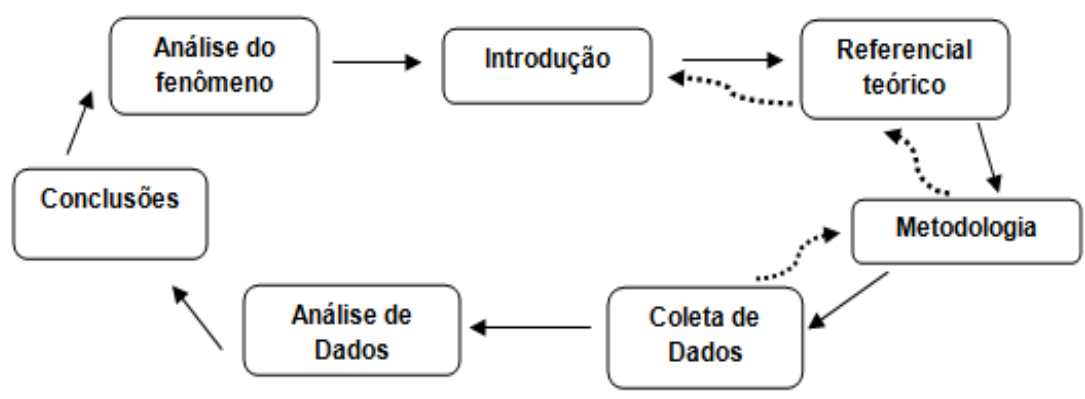

Fonte: Elaboração própria.

O objetivo de seguir uma metodologia é bem mais que levar o aluno a elaborar trabalhos acadêmicos, é dispor um propósito para levar o discente a ter uma comunicação de forma clara, direta, compreensível, desenvolvendo um raciocínio lógico, bem constituído e conciso. Pinto (2005) descreve que o método, quando incorporado a uma forma de trabalho ou de pensamento, leva o indivíduo a adquirir hábitos e posturas diante de si mesmo, do outro e do mundo que só têm a beneficiar a sua vida tanto profissional quanto social, afetiva, econômica e cultural. Por método entende-se o caminho que se trilha para alcançar um determinado fim e se atingir um objetivo. Além disso, o referido autor revela que as regras e passos metodológicos que são ensinados na universi- 
dade, visando à inserção do estudante no mundo acadêmico-científico, que são pertinentes e necessários, objetivam também criar hábitos que o acompanharão por toda a sua vida, como o gosto pela leitura, a compreensão dos diferentes interlocutores, desenvolvimento de espírito crítico maduro e responsável, diálogo claro e profundo com os outros e com o mundo, a autodisciplina, o respeito à alteridade e ao diferente, uma postura de humildade diante do pouco que se sabe e da infinidade de saberes existentes, o exercício da ética e do respeito à quem pensa diferente, a ousadia/coragem de expor o próprio pensar.

\subsubsection{Aspecto Relacional}

O nível de orientação, ou o aspecto relacional, representa todo o processo de relação entre o profissional de ensino (orientador) e o aluno (orientando), através de diferentes perspectivas (Medeiros et al., 2011).

O docente e o discente são pessoas que se encontram para compartilhar uma trajetória até a conclusão do TCC, e como ambos são seres humanos, esse relacionamento é dotado de sentimentos dúbios como qualquer relação que faz parte da convivência humana, podendo oscilar de amor ao ódio, da aceitação à rejeição (Quixadá-Viana \& Veiga, 2007).

Segundo Alexandre (2003), o conhecimento, a iniciativa, a dedicação, a humildade e o respeito são qualidades exigidas do estudante para a realização de um trabalho de pesquisa. Entretanto, mesmo com essas qualidades, o aluno pode se deparar com uma má orientação, surgindo alguns inconvenientes durante o processo (Medeiros et al., 2011).

O professor com toda sua experiência e seus conhecimentos sobre o assunto abordado, deve acompanhar todo o processo de composição do trabalho científico do aluno, buscando ajudá-lo a descobrir o que é investigar, bem como em questões nos quais o orientando tenha dificuldades (Bianchetti, 2006).

Conforme o trabalho de Medeiros et al. (2015), a visão do orientador sobre o contexto relacional no processo de orientação de TCC's é demonstrada através de quatro aspectos: interesse e dedicação, afinidade com o orientador, comunicação e cooperação.

\subsection{Estudos Anteriores}

De acordo com a pesquisa de literatura, o Quadro 1 apresenta alguns trabalhos relacionados com o tema estudado sobre processo de orientação de trabalhos de conclusão de curso.

Quadro 1 - Relação de estudos realizados sobre o processo de orientação de TCC na visão dos docentes.

\begin{tabular}{|c|c|c|}
\hline Autor / Ano & Objetivo & Resultados \\
\hline $\begin{array}{l}\text { Carboni \& } \\
\text { Nogueira } \\
(2004) .\end{array}$ & $\begin{array}{l}\text { Caracterizar o perfil } \\
\text { dos graduandos do } 8^{-} \\
\text {semestre do curso de } \\
\text { Enfermagem de uma } \\
\text { escola privada e identi- } \\
\text { ficar os fatores que faci- } \\
\text { litam e dificultam a ela- } \\
\text { boração do TCC. }\end{array}$ & $\begin{array}{l}\text { A existência de uma estrutura apropriada para pesquisa (a definição } \\
\text { de temas, o espaço para a realização do trabalho, o orientador e a bi- } \\
\text { bliografia) foi considerada um facilitador para a realização do TCC. } \\
\text { Existe uma correlação positiva entre as condições socioeconômicas } \\
\text { dos entrevistados e os fatores 'tempo' e 'custos', assinalados como } \\
\text { os principais dificultadores do processo. Existe uma correlação ne- } \\
\text { gativa entre o número de professores orientadores e a quantidade } \\
\text { de alunos que necessitam elaborar o TCC. Há diferenças de expecta- } \\
\text { tivas entre os agentes pedagógicos e os estudantes quanto à vincula- } \\
\text { ção do TCC ao término do curso e ao recebimento do diploma. }\end{array}$ \\
\hline $\begin{array}{l}\text { Cruz, Corrar } \\
\text { \& Slomski } \\
(2008) .\end{array}$ & $\begin{array}{l}\text { Comparar o desempe- } \\
\text { nho de alunos dos cur- } \\
\text { sos de graduação em } \\
\text { Ciências Contábeis no } \\
\text { Brasil levando-se em } \\
\text { consideração determi- } \\
\text { nados aspectos da do- } \\
\text { cência e recursos físicos } \\
\text { educacionais. }\end{array}$ & $\begin{array}{l}\text { Verificou-se, pelos resultados dos testes estatísticos, que os docentes } \\
\text { tiveram influência no desempenho dos seus educandos. A perfor- } \\
\text { mance dos alunos que tiveram suas aulas ministradas por professo- } \\
\text { res com domínio atualizado das disciplinas foi melhor que aqueles } \\
\text { cujas aulas foram dadas por docentes, que em sua maioria, não esta- } \\
\text { vam atualizados. Diferentes técnicas de ensino também provocaram } \\
\text { diferentes desempenhos. Além disso, os alunos que realizaram ati- } \\
\text { vidades de pesquisa como estratégia de aprendizagem tiveram me- }\end{array}$ \\
\hline
\end{tabular}




\begin{tabular}{|l|l|l|}
\hline \multirow{1}{*}{} & & $\begin{array}{l}\text { lhor performance que aqueles que não realizaram. Quanto aos re- } \\
\text { cursos didáticos, os estudantes que utilizaram predominantemente } \\
\text { livros, por indicação dos professores, apresentaram melhor desem- } \\
\text { penho que aqueles que usaram apostilas e resumos, cópias de tre- } \\
\text { chos de livros, artigos de periódicos especializados ou anotações } \\
\text { manuais. Alunos que tiveram pleno acesso a microcomputadores al- } \\
\text { cançaram melhor desempenho que aqueles que não tiveram. Já um } \\
\text { ambiente especializado para estudo não impactou o desempenho } \\
\text { dos alunos. }\end{array}$ \\
\hline al. (2015). & $\begin{array}{l}\text { Identificar dificuldades } \\
\text { do processo de orienta- } \\
\text { ção em TCC's, sob a } \\
\text { percepção dos docentes } \\
\text { do curso de uma IES } \\
\text { privada. }\end{array}$ & $\begin{array}{l}\text { Observou-se que algumas questões podem dificultar o processo de } \\
\text { orientação em TCC's, sejam relacionadas diretamente às característi- } \\
\text { cas dos docentes, bem como a forma e o envolvimento durante a } \\
\text { construção de trabalho com os discentes. Pode-se destacar as se- } \\
\text { guintes questões como possíveis características que dificultam este } \\
\text { processo de orientação: No aspecto cognitivo, a baixa participação } \\
\text { dos pesquisados em atividades de pesquisa e extensão, bem como o } \\
\text { elevado número de TCC's orientados por eles; no aspecto operacio- } \\
\text { nal, a metodologia, a redação e a conclusão desenvolvidas pelos alu- } \\
\text { nos durante a construção do trabalho de conclusão de curso, e no as- } \\
\text { pecto de relacionamento, a falta de interesse e dedicação. }\end{array}$ \\
\hline
\end{tabular}

Fonte: Elaboração própria, como base nos estudos anteriores.

Dos estudos apresentados no Quadro 1, o presente trabalho se diferencia dos realizados por Caborni e Nogueira (2004) e Cruz et al. (2008) por estes terem como público alvo graduandos dos cursos de Enfermagem e Ciências Contábeis, respectivamente. Os aspectos abordados nos trabalhos foram os que identificassem fatores que facilitam e dificultam a elaboração do TCC, bem como a análise do desempenho dos alunos no Exame Nacional de Cursos - Provão do ano de 2002, levando em consideração os aspectos da docência e os recursos físicos educacionais. O presente trabalho foi baseado no de Medeiros et al. (2015), diferenciando-se em relação ao público alvo, uma vez que Medeiros et al. (2015) direcionaram sua pesquisa para o curso de Administração, enquanto neste trabalho, o foco são os professores que lecionam nos cursos de Ciências Contábeis, de forma a verificar congruências e discrepâncias que os resultados possam apontar, em relação as dificuldades encontradas na realidade de outro curso.

\section{METODOLOGIA}

Para avaliar as dificuldades do processo de orientação, foi desenvolvida uma pesquisa com docentes do curso de Ciências Contábeis em instituições particulares e públicas de ensino superior na cidade do Recife e Ipojuca, envolvidos na orientação de TCC's.

Quanto à natureza da pesquisa, foi realizado um estudo quantitativo, que de acordo com Mascarenhas (2012) baseia-se na quantificação para coletar e tratar os dados obtidos utilizando técnicas estatísticas, tais como: porcentagens, médias e desvio padrão, tornando o estudo mais imparcial para evitar influência do pesquisador sobre os resultados.

Como instrumento para coleta de dados da pesquisa, foi aplicado questionário embasado no trabalho de Medeiros et al. (2015). O questionário foi composto por vinte e duas perguntas fechadas de múltipla escolha, tendo o respondente que optar por uma das alternativas apresentadas, com exceção das questões referentes à formação acadêmica e a área em que atua na graduação, visto que os docentes podem tanto terem mais de uma formação acadêmica quanto atuar em outros cursos de graduação. As questões foram estruturadas em quatro blocos, que dizem respeito, primeiramente, ao perfil do docente de Ciências Contábeis. Em seguida foram abordados os aspectos cognitivos, destacando as questões metodológicas. O terceiro bloco referiu-se aos aspectos operacionais que estão relacionados à elaboração do documento (planejamento de pesquisa) e o quarto bloco abrangeu os aspectos relacionais inseridos no processo de orientação. 
No mês de fevereiro de 2017, foi efetuado um pré-teste com uma amostra reduzida de participantes, sendo escolhidos três docentes aleatoriamente de uma instituição particular de ensino superior na cidade do Recife, com o objetivo de identificar problemas na elaboração das questões e realizar eventuais ajustes. De acordo com Creswell (2007), o teste de campo "é importante para estabelecer a validade de conteúdo de um instrumento e para melhorar questões, formatos e escalas". Foi identificado no pré-teste a necessidade de ajustar o questionário a partir da décima questão, tendo em vista que as respostas de múltiplas escolhas eram iguais, bem como acrescentar mais uma opção nas alternativas, sendo "não atende as expectativas".

Os docentes foram questionados por meio de um questionário com vinte e duas questões: nove fechadas de múltipla escolha e treze mensuradas por meio de escala do tipo Likert (em 6 pontos), redefinida como: 1 (não atende as expectativas), 2 (atende a poucas expectativas), 3 (atende a algumas expectativas), 4 (atende a maioria das expectativas), 5 (atende a todas expectativas) e 6 (excede as expectativas). A escala de Likert é usada para medir concordância de pessoas a determinadas afirmações relacionadas a construtos de interesse, sendo que a escala original seria aplicada com cinco pontos, mas atualmente existem modelos chamados do tipo Likert com variações nas pontuações, dependendo do critério do pesquisador (Silva Júnior \& Costa, 2014).

A coleta de dados foi realizada nas instituições particulares e públicas de ensino superior na cidade do Recife e Ipojuca com a entrega do questionário impresso aos docentes do curso de Ciências Contábeis, no período de março a abril de 2017.

O questionário teve sua consistência interna testada através do Alfa de Cronbach, que demonstra a confiabilidade interna do instrumento de coleta. O coeficiente Alfa de Cronbach, segundo Hora, Monteiro \& Arica (2010), é uma forma de estimar a confiabilidade de um questionário aplicado em uma pesquisa, onde o alfa mede a correlação entre respostas em um questionário através da análise do perfil das respostas dadas pelos respondentes.

Feita a coleta, procedeu-se a organização e tabulação dos dados que foram desenvolvidos a partir do software Microsoft Excel. Em seguida foi utilizado o software Statistical Package for Social Sciences - SPSS 20.0 para análise dos dados.

Na primeira parte da pesquisa foi verificado o perfil dos docentes considerando o tempo de atuação no ensino superior, a formação acadêmica e a área de atuação no ensino superior.

A análise do aspecto cognitivo, segunda parte do questionário, levou em consideração o nível acadêmico dos pesquisados, a atuação na pós-graduação e em atividades de pesquisa e extensão, o volume de orientações prestadas em TCC's, participação em bancas examinadoras e publicações em anais e eventos científicos.

A terceira parte abordou as questões operacionais que foram subdivididas em dois momentos, o aspecto operacional I e II. As questões do aspecto operacional I disseram respeito à relevância do tema, justificativa, problemática, referencial teórico, metodologia, redação e conclusão, Já o no aspecto operacional II foi abordado o cumprimento do cronograma, das normas do trabalho e as referências consultadas.

$\mathrm{O}$ aspecto relacional introduzido no processo de elaboração de TCC's constituiu a quarta parte, abordando-se itens como interesse, afinidade com o orientador, comunicação e cooperação.

\section{ANÁLISE DOS RESULTADOS}

\subsection{Confiabilidade e Coeficiente Alfa de Cronbach}

Foi rodado o teste Alfa de Cronbach utilizando o software Statistical Package for Social Sciences - SPSS 20.0 para a análise das questões dos aspectos cognitivo, operacional e relacional. De acordo com Matthiensen (2011), os valores de alfa variam de 0 a 1,0; quanto mais próximo de 1, maior confiabilidade entre os indicadores. $\mathrm{O}$ teste demonstrou que o coeficiente Alfa de Cronbach encontrado foi de 0,917 , conforme Tabela 1. 
Tabela 1 - Alfa de Cronbach.

Alfa de Cronbach 0,917
Alfa de Cronbach com base em itens padronizados 0,902

Fonte: Dados da pesquisa.

Isso quer dizer que o questionário teve uma boa consistência interna, pois conforme apontado por Matthiensen (2011), o coeficiente Alfa de Cronbach entre 0,70 e 0,90 é aceitável, ou seja, o valor de alfa encontrado no estudo é satisfatório.

\subsection{Parte I: Perfil dos Docentes}

Os docentes analisados estavam vinculados ao ensino superior no curso de Ciências Contábeis e foram questionados sobre o tempo de atuação, formação acadêmica e a área de atuação no ensino superior. A pesquisa foi realizada com 31 docentes do curso de Ciências Contábeis em instituições particulares e públicas de ensino superior envolvidos na orientação de TCC's, na cidade do Recife e Ipojuca, Pernambuco.

Em relação ao tempo de atuação dos docentes no ensino superior, 32\% atuam entre 0 e 5 anos; $29 \%$ atuam entre 6 e 10 anos; $13 \%$ atuam entre 11 e 15 anos, e $26 \%$ atuam há mais de 15 anos;.

Sobre a questão da formação acadêmica, $74 \%$ são formados em Ciências Contábeis; $6 \%$ são formados em Economia; 3\% são formados em Direito; e 16\% são formados em mais de um curso tais como Administração, Ciências Contábeis, Direito e Matemática.

Em se tratando da área de atuação dos docentes na graduação, observa-se que a maioria dos docentes (65\%) atua apenas no curso de Ciências Contábeis, enquanto 35\% atuam tanto no curso de Ciências Contábeis como em outros cursos de graduação, como Administração, Direito, Economia e Turismo. Os respondentes poderiam optar por mais de uma das alternativas apresentadas nas questões referentes à formação acadêmica e a área de atuação na graduação.

Tabela 2 - Resumo do perfil dos docentes.

\begin{tabular}{cll}
\hline QUESTÕES INVESTIGADAS & \multicolumn{1}{c}{ PERFIL DA AMOSTRA ESTUDADA } \\
\hline \multirow{2}{*}{$\begin{array}{c}\text { Tempo de atuação no ensino supe- } \\
\text { rior }\end{array}$} & Entre 0 a 5 anos. & $32 \%$ \\
& Entre 6 a 10 anos. & $29 \%$ \\
& Entre 11 a 15 anos. & $13 \%$ \\
& Mais que 15 anos. & $26 \%$ \\
\hline \multirow{2}{*}{ Formação acadêmica } & Apenas em Ciências Contábeis. & $74 \%$ \\
& Apenas em Economia. & $6 \%$ \\
& Apenas em Direito. & $3 \%$ \\
\hline \multirow{2}{*}{ Área de atuação na graduação } & Mais de um curso superior. & $16 \%$ \\
\hline
\end{tabular}

Fonte: Dados da pesquisa.

\subsection{Parte II: Aspecto Cognitivo}

Na segunda parte, a análise do aspecto cognitivo levou em consideração o nível acadêmico dos pesquisados, a atuação na pós-graduação e em atividades de pesquisa e extensão, o número de orientações prestadas em TCC's nos dois últimos semestres, o número de participações em bancas examinadoras nos dois últimos semestres e o número de publicações em anais e eventos científicos e periódicos nos dois últimos semestres.

No que se refere ao nível acadêmico dos pesquisados, observa-se na Tabela 3 que a maior parte dos docentes possui o nível acadêmico de mestrado, com $58 \%$, enquanto $39 \%$ possuem o nível de doutorado e $3 \%$ possuem o nível de especialização. 
Tabela 3 - Nível acadêmico dos docentes.

\begin{tabular}{c|c}
\hline Especialista & $3 \%$ \\
\hline Mestre & $58 \%$ \\
\hline Doutor & $39 \%$ \\
\hline
\end{tabular}

Fonte: Dados da pesquisa.

Os resultados foram corroborados pelo estudo de Medeiros et al. (2015), em que a maioria dos docentes questionados possuíam a titulação de mestrado, com $76 \%$, enquanto que $24 \%$ possuíam o nível de especialização. Para Medeiros et al. (2015), quanto maior for o nível acadêmico, maior será a exigência de uma base de conhecimentos que esse profissional deve ter e melhor será sua visão acadêmica. Dessa forma, verificou-se que nas instituições de ensino superior pesquisadas existem docentes do curso de Ciências Contábeis que orientam a elaboração de TCC's, com alto nível acadêmico.

Os dados apresentados na Tabela 4 mostram os resultados de duas questões relacionadas ao aspecto cognitivo, à atuação do docente na pós-graduação e em atividades de pesquisa e extensão. Na primeira questão observa-se que $71 \%$ dos pesquisados atuam na pós-graduação.

Tabela 4 - Atuação dos docentes fora da graduação.

\begin{tabular}{c|c|c}
\hline \multirow{2}{*}{ Atua na pós-graduação? } & Sim & $71 \%$ \\
\cline { 2 - 3 } & Não & $29 \%$ \\
\hline \multirow{2}{*}{ Atua em atividade de pesquisa e extensão? } & Sim & $84 \%$ \\
\cline { 2 - 3 } & Não & $16 \%$ \\
\hline
\end{tabular}

Fonte: Dados da pesquisa.

Esse resultado corroborou com a pesquisa de Medeiros et al. (2015), que mostrou que 90\% dos pesquisados atuavam na pós-graduação. Já na segunda questão, observa-se que $84 \%$ dos questionados atuam em atividades de pesquisa e extensão, não corroborando com a pesquisa de Medeiros et al. (2015), em que 57\% não atuavam em atividades de pesquisa e extensão. De acordo com Bianchetti (2006), um profissional do ensino propõe-se a ser um bom orientador uma vez que ele pratica o ato de realizar pesquisa, sendo mais evidente no nível de doutorado.

A análise do número de orientações prestadas em TCC's nos últimos dois semestres foi outro ponto pesquisado. De acordo com os resultados da Tabela 5, observa-se que $29 \%$ dos pesquisados tiveram entre 4 e 6 orientações, como também $29 \%$ dos questionados tiveram mais de 10 orientações, enquanto $23 \%$ tiveram entre 1 e 3 orientações e 19\% tiveram entre 7 e 10 orientações.

Tabela 5 - Número de orientações prestadas em TCC's nos dois últimos semestres.

\begin{tabular}{lc}
\hline Número de orientações & Respondentes \\
\hline De 1 a 3 & $23 \%$ \\
De 4 a 6 & $29 \%$ \\
De 7 a 10 & $19 \%$ \\
Mais de 10 & $29 \%$ \\
\hline
\end{tabular}

Fonte: Dados da pesquisa.

Medeiros et al. (2015) revelaram que quanto maior for o número de orientações, maior será a dificuldade de entendimento e atenção aplicada do orientador em relação aos trabalhos, tendo o orientador que ter maior atenção e dedicar maior tempo no processo de leitura, interpretação e orientações destes trabalhos. Com isso, observou-se nos resultados desta pesquisa que o número de orientações é um indicador para avaliar a qualidade da orientação. 
No que se refere à participação dos docentes em bancas examinadoras nos últimos dois semestres, a pesquisa mostra que 32\% dos pesquisados tiveram participação de 1 a 5 bancas examinadoras, enquanto $26 \%$ tiveram participação que variaram entre 6 a 10 bancas, como também 16\% estiveram entre 11 a 15 bancas de avaliação e $26 \%$ tiveram participação em bancas examinadoras superior a 15 (Tabela 6).

Tabela 6 - Número de participações em bancas examinadoras nos dois últimos semestres.

\begin{tabular}{cc}
\hline Número de participações & Respondentes \\
\hline De 1 a 5 & $32 \%$ \\
De 6 a 10 & $26 \%$ \\
De 11 a 15 & $16 \%$ \\
Mais de 15 & $26 \%$ \\
\hline
\end{tabular}

Fonte: Dados da pesquisa.

O resultado deste estudo apresentou diferença de $6 \%$ entre números de orientadores que menos participaram (32\%) em bancas examinadoras e que mais participaram (26\%). Para Medeiros et al. (2015), a participação em bancas examinadoras é um importante critério, no sentido de ampliar a visão e ter diferentes perspectivas de avaliação diante de outros docentes, assim como desenvolver questões que refletem no processo de orientação, logo, quanto maior for a participação, maior será a ajuda do docente na identificação de características que possuem maior influência na avaliação dos TCC's.

A Tabela 7 apresenta os resultados referentes ao número de publicações em anais e eventos científicos nos dois últimos semestres. Observa-se que a maior parte dos docentes pesquisados, cerca de $48 \%$, possuíam publicações que variaram entre 0 e 3, enquanto $26 \%$ variaram entre 4 e 6 publicações, $19 \%$ possuíam publicações superior a 10, e 6\% variaram entre 7 e 10 publicações.

Tabela 7 - Número de publicações em anais e eventos científicos e periódicos nos dois últimos semestres.

\begin{tabular}{cc}
\hline Número de publicações & Respondentes \\
\hline De 0 a 3 & $48 \%$ \\
De 4 a 6 & $26 \%$ \\
De 7 a 10 & $6 \%$ \\
Mais de 10 & $19 \%$ \\
\hline
\end{tabular}

Fonte: Dados da pesquisa.

O resultado referente ao número de publicações em anais e eventos científicos corroborou com o da pesquisa de Medeiros et al. (2015), na qual mostrou que a maior parte dos pesquisados, em torno de $76 \%$, possuíam publicações que variaram entre 0 e 3 . Conforme esse autor, o baixo número de produção científica publicada pode refletir no entendimento de questões relacionadas à produção científica, principalmente em aspectos metodológicos e no trabalho de orientação dos TCC's.

\subsection{Parte III: Aspecto Operacional}

A terceira parte abordou as questões operacionais, que foram apresentadas subdivididas em dois momentos denominados de aspecto operacional I e aspecto operacional II, ambos, relacionados à etapa de planejamento da pesquisa. As questões levantadas no aspecto operacional I (Tabela 8) dizem respeito à relevância do tema, justificativa, problemática e objetivos, referencial teórico, metodologia, redação, conclusão. Com relação a estes pontos observou-se que a "redação" foi o único aspecto em que foi selecionada a opção "não atende as expectativas" com 3\%, revelando que neste ponto a visão de alguns docentes é bastante crítica em relação à escrita dos orientandos. Além dessa 
resposta, nota-se que $16 \%$ dos docentes apontaram a opção "atende a poucas expectativas", enquanto 39\% apontaram a opção "atende a algumas expectativas", o que revela a tendência negativa dos docentes em relação a redação dos seus orientandos.

Tabela 8 - Aspecto Operacional I.

\begin{tabular}{ccccccc}
\hline & $\begin{array}{c}\text { Não atende } \\
\text { as expectati- } \\
\text { vas }\end{array}$ & $\begin{array}{c}\text { Atende a } \\
\text { poucas ex- } \\
\text { pectativas }\end{array}$ & $\begin{array}{c}\text { Atende a al- } \\
\text { gumas ex- } \\
\text { pectativas }\end{array}$ & $\begin{array}{c}\text { Atende a } \\
\text { maioria das } \\
\text { expectativas }\end{array}$ & $\begin{array}{c}\text { Atende a to- } \\
\text { das expecta- } \\
\text { tivas }\end{array}$ & $\begin{array}{c}\text { Excede as ex- } \\
\text { pectativas }\end{array}$ \\
\hline $\begin{array}{c}\text { Relevância } \\
\text { do tema }\end{array}$ & $0 \%$ & $6 \%$ & $39 \%$ & $39 \%$ & $13 \%$ & $3 \%$ \\
$\begin{array}{c}\text { Justificativa, } \\
\text { problemática } \\
\text { e objetivos }\end{array}$ & $0 \%$ & $10 \%$ & $39 \%$ & $35 \%$ & $13 \%$ & $3 \%$ \\
$\begin{array}{c}\text { Referencial } \\
\text { Teórico }\end{array}$ & $0 \%$ & $35 \%$ & $29 \%$ & & & \\
$\begin{array}{c}\text { Metodologia } \\
\text { Redação }\end{array}$ & $0 \%$ & $10 \%$ & $42 \%$ & $35 \%$ & $10 \%$ & $3 \%$ \\
Conclusão & $0 \%$ & $16 \%$ & $39 \%$ & $29 \%$ & $13 \%$ & $0 \%$ \\
\hline
\end{tabular}

Fonte: Dados da pesquisa.

Esse resultado corroborou com a pesquisa de Medeiros et al. (2015), que sugeriu que no aspecto operacional I a maior dificuldade dos alunos de Administração durante o processo de elaboração de TCC's estava na redação.

Os outros pontos do aspecto operacional I também se confirmaram com os resultados apresentados por Carboni e Nogueira (2004) no trabalho sobre as facilidades e dificuldades na elaboração de TCC sob a visão de alunos de enfermagem, destacando-se a obrigatoriedade de existir uma metodologia como um fator importante para elaboração de uma pesquisa. De acordo com esses autores, existe uma dificuldade em assimilar o método a ser seguido, a forma como as referências devem ser citadas, a lógica que deve existir, a maneira como os resultados devem ser apresentados, a importância da coerência entre o tema, o problema, os objetivos, o método e a conclusão.

As questões do aspecto operacional II abordaram o cumprimento do cronograma e das normas do trabalho e as referências consultadas. Através dos resultados obtidos, apresentados na Tabela 9, nota-se que nos três quesitos, em torno de $27 \%$ dos docentes consideraram que o desempenho dos alunos "atende a maioria das expectativas". Porém, cerca de 39\% dos docentes que responderam à pesquisa julgou que o cumprimento das normas de trabalho "atendeu a algumas expectativas".

Tabela 9 - Aspecto Operacional II.

\begin{tabular}{ccccccc}
\hline & $\begin{array}{c}\text { Não atende } \\
\text { as expectati- } \\
\text { vas }\end{array}$ & $\begin{array}{c}\text { Atende a } \\
\text { poucas ex- } \\
\text { pectativas }\end{array}$ & $\begin{array}{c}\text { Atende a al- } \\
\text { gumas ex- } \\
\text { pectativas }\end{array}$ & $\begin{array}{c}\text { Atende a } \\
\text { maioria das } \\
\text { expectativas }\end{array}$ & $\begin{array}{c}\text { Atende a to- } \\
\text { das expecta- } \\
\text { tivas }\end{array}$ & $\begin{array}{c}\text { Excede as } \\
\text { expectativas }\end{array}$ \\
\hline $\begin{array}{c}\text { Cumprimento do } \\
\text { cronograma }\end{array}$ & $13 \%$ & $10 \%$ & $35 \%$ & $26 \%$ & $13 \%$ & $3 \%$ \\
$\begin{array}{c}\text { Cumprimento } \\
\text { das normas do }\end{array}$ & $3 \%$ & $10 \%$ & $39 \%$ & $29 \%$ & $16 \%$ & $3 \%$ \\
$\begin{array}{c}\text { trabalho } \\
\text { Referências con- } \\
\text { sultadas }\end{array}$ & $3 \%$ & $23 \%$ & $32 \%$ & $26 \%$ & $13 \%$ & $3 \%$ \\
\hline
\end{tabular}

Fonte: Dados da pesquisa

Os resultados não corroboraram com os do trabalho de Medeiros et al. (2015). Segundo eleS, os aspectos que dificultaram o processo de elaboração dos TCC's dos alunos de Administração foram o cumprimento do cronograma e as referências consultadas. 


\subsection{Parte IV: Aspecto Relacional}

O aspecto relacional introduzido no processo de elaboração de TCC's constituiu na quarta parte do questionário. Foram investigados itens como interesse e dedicação, afinidade com o orientador, comunicação e cooperação.

Na Tabela 10 observa-se que dos itens abordados, mais de 35\% dos docentes consideraram atender a maioria das expectativas, sendo a "afinidade com o orientador" o fator de melhor desempenho, onde $48 \%$ consideraram atender a maioria das expectativas e $35 \%$ julgaram atender a todas as expectativas.

Tabela 10 - Aspecto Relacional.

\begin{tabular}{ccccccc}
\hline & $\begin{array}{c}\text { Não atende } \\
\text { as expectati- } \\
\text { vas }\end{array}$ & $\begin{array}{c}\text { Atende a } \\
\text { poucas ex- } \\
\text { pectativas }\end{array}$ & $\begin{array}{c}\text { Atende a al- } \\
\text { gumas ex- } \\
\text { pectativas }\end{array}$ & $\begin{array}{c}\text { Atende a } \\
\text { maioria das } \\
\text { expectativas }\end{array}$ & $\begin{array}{c}\text { Atende a to- } \\
\text { das expecta- } \\
\text { tivas }\end{array}$ & $\begin{array}{c}\text { Excede as } \\
\text { expectativas }\end{array}$ \\
\hline $\begin{array}{c}\text { Interesse e dedi- } \\
\text { cação }\end{array}$ & $0 \%$ & $10 \%$ & $42 \%$ & $42 \%$ & $6 \%$ & $0 \%$ \\
$\begin{array}{c}\text { Afinidade com o } \\
\text { orientador }\end{array}$ & $0 \%$ & $0 \%$ & $16 \%$ & $48 \%$ & $35 \%$ & $0 \%$ \\
Comunicação & $0 \%$ & $6 \%$ & $29 \%$ & $42 \%$ & $19 \%$ & $3 \%$ \\
Cooperação & $0 \%$ & $3 \%$ & $39 \%$ & $35 \%$ & $23 \%$ & $0 \%$ \\
\hline
\end{tabular}

Fonte: Dados da pesquisa.

Esse resultado corroborou tanto com o estudo de Medeiros et al. (2015), no qual o item "afinidade com o orientador" teve a melhor representação, onde $57 \%$ consideraram atender a maioria das expectativas e 33\% julgaram atender a todos as expectativas, quanto com o trabalho de Cunha, Vogt \& Biavatti (2015), tendo esse aspecto um ponto importante para o desenvolvimento do TCC.

Dentre os outros aspectos pesquisados destacou-se o "interesse e dedicação", "comunicação" e "cooperação" com um desempenho regular, já que nestes três itens 10\%, 6\% e 3\%, respectivamente, obtiveram respostas dos docentes com a opção atende a poucas expectativas.

Barbosa e Theóphilo (2007), que analisaram as dificuldades no desenvolvimento de monografias na percepção dos discentes do curso de Ciências Contábeis, identificaram que 24,68\% dos alunos julgam a desmotivação como uma das dificuldades no processo de elaboração do TCC. O aspecto "interesse e dedicação" está relacionada com a motivação, observando-se que $42 \%$ dos pesquisados consideraram que o interesse e dedicação dos alunos atende a algumas expectativas, o que corrobora com o estudo de Medeiros et al. (2015), onde 43\% dos docentes julgaram que o item "interesse e dedicação" atende a algumas expectativas, sendo um fator que influencia no processo de elaboração dos TCC's.

\section{CONCLUSÃO}

O objetivo do estudo foi identificar as dificuldades do processo de orientação em TCC's, sob a percepção dos docentes de Ciências Contábeis de Instituições de Ensino Superior na cidade de Recife e Ipojuca, como também analisar o perfil dos docentes e verificar sob o aspecto cognitivo, operacional e relacional o comprometimento dos alunos na elaboração dos TCC's.

Respondendo aos objetivos da pesquisa, constatou-se que algumas questões analisadas revelam problemas a serem enfrentados durante a orientação dos TCC's que podem dificultar o processo de orientação.

Sobre as dificuldades encontradas em relação ao aspecto cognitivo observou-se que a maioria dos docentes apresentou muitas orientações durante os últimos dois semestres. Logo, esse fato pode ser um indicador para avaliar a qualidade das orientações, pois quanto mais orientações tiverem, 
poderá aparecer dificuldades na percepção, compreensão e concentração em relação aos trabalhos, já que o orientador terá que disponibilizar mais atenção e ceder mais tempo durante as leituras dos mesmos e indicar as direções que os orientandos devem seguir.

No aspecto operacional a dificuldade que os orientadores possuem é na redação dos seus orientandos nos trabalhos, bem como, por parte dos discentes, a falta de assimilar e seguir a metodologia, o cronograma, o conhecimento das normas e formas como as referências devem ser citadas, a lógica que deve seguir, a maneira como os resultados devem ser apresentados, por fim, a importância da correlação entre o tema, o problema, os objetivos, o método e a conclusão. Pode-se atribuir a tais resultados, o fato de que muitos estudantes tem pouco acesso a atividades de natureza científica ao longo do curso, de forma a amadurecer este tipo de conhecimento antes da elaboração do trabalho final.

Em relação ao aspecto relacional as opções de "interesse e dedicação", "comunicação" e "cooperação" foram as únicas que apresentaram a resposta que os orientados atendem a poucas expectativas. Diante disto, os orientandos ao apresentar falta de interesse, dedicação, comunicação e colaboração durante a realização do TCC podem dificultar o processo de orientação.

Esta pesquisa revelou a necessidade de expor os problemas que ocorrem durante as orientações das pesquisas acadêmicas através da visão do docente, para que possa evitar um baixo desempenho dos envolvidos no processo durante o processo de elaboração do TCC. Com isso, toma-se como sugestão a realização de ações e projetos nas IES no intuito de desenvolver o conhecimento dos alunos através de práticas de como elaborar um trabalho científico.

Sugere-se também o desenvolvimento de pesquisas dentro de disciplinas no decorrer do curso como estratégia que garanta o aprendizado no aspecto operacional dos alunos, para que no encerramento do curso não tenham dificuldades na execução dos projetos de TCC's.

\section{REFERÊNCIAS}

Alencar, L. B. (2016). Práticas de orientação de TCC em curso de graduação em ciências contábeis em IES da cidade de São Paulo que possuem stricto sensu. Dissertação de mestrado, Fundação Escola de Comércio Álvares Penteado - FECAP, São Paulo, SP, Brasil.

Alexandre, M. J. O. (2003) A construção do trabalho científico: um guia para projetos, pesquisas e relatórios científicos. Rio de Janeiro: Forense Universitária.

Almeida, A. F. M.; \& Leal, E. A. (2015) Características do Trabalho de Conclusão de Curso de Ciências Contábeis em Universidades Públicas de Minas Gerais. In: $6^{0}$ Congresso UFSC de Iniciação Científica em Contabilidade, Santa Catarina.

Associação Brasileira de Normas Técnicas. NBR 14724: Informação e documentação: trabalhos acadêmicos: apresentação. Rio de Janeiro, 2011.

Barbosa, K.; \& Theóphilo, C. R. (2007). Análise do processo de elaboração de monografias pelos alunos do curso de Ciências Contábeis de uma Universidade do norte de Minas Gerais. In: $7^{0}$ Congresso USP de Controladoria e Contabilidade, São Paulo.

Bianchetti, L.; \& Machado, A. M. N. (2006). A bússola do escrever: desafios e estratégias na orientação e escritas de teses e dissertações. 2 ed. Florianópolis: Ed. da UFSC; São Paulo: Cortez.

Boso, A. K., Garcia, D., Rodrigues, M. B., \& Marcondes, P. (2010). Aspectos cognitivos da leitura: conhecimento prévio e teoria dos esquemas. Revista $A C B, 15(2), 24-39$. 
Brasil. Conselho Nacional de Educação. Câmara de Educação Superior. Resolução CNE/CES n. 10, de 16 de dezembro de 2004. Institui as Diretrizes Curriculares Nacionais para o Curso de Graduação em Ciências Contábeis, bacharelado, e dá outras providências. Brasília: MEC, 2004.

. Ministério de Educação e Cultura. LDB - Lei no 9394/96, de 20 de dezembro de 1996. Estabelece as diretrizes e bases da Educação Nacional. Brasília: MEC, 1996.

Brizolla, M. M. B., Basso, L.; \& Soschinski, C. K. (2014). Temas de pesquisa em TCC's de Ciências Contábeis. Anais Salão do Conhecimento, Ijuí, RS, Brasil, 22.

Brunozi Júnior, A. C., Emmendoerfer, M. L., Abrantes, L. A., \& Contelli Klein, T. (2011). REVISTA CONTABILIDADE \& FINANÇAS-USP: UMA ANÁLISE DO PERFIL DA PRODUÇÃO CIENTÍFICA DE 1989 A 2009. Revista Universo Contábil, 7(4).

Campos, F. G. G., Santos, R. F.; \& Santos, F. C. P. (2009).A Importância da Pesquisa Científica na formação profissional dos alunos do curso de Educação Física do UNILESTEMG. Movimentum, v. 4.

Carboni, R. M.; \& Nogueira, V. O. (2004) Facilidades e dificuldades na elaboração de trabalhos de conclusão de curso. ConScientiae Saúde, n. 3, p. 65-72, São Paulo: UNINOVE.

Carneiro, J.D. (Coord.). (2009). Proposta nacional de conteúdo para o curso de graduação em Ciências Contábeis. 2.ed. rev. e atual. Brasília: Fundação Brasileira de Contabilidade.

Creswell, J. W. (2007). Projeto de Pesquisa: métodos qualitativo, quantitativo e misto. 2. ed. Porto Alegre: Artmed.

Cruz, C. V. O. A.; Corrar, L. J.; Slomski, V. A. (2008). docência e o desempenho dos alunos dos cursos de graduação em Contabilidade no Brasil. Revista Contabilidade Vista \& Revista, ISSN 0103-734X, Universidade Federal de Minas Gerais, Belo Horizonte, v. 19, n. 4, p. 15-37.

Cunha, L. C., Vogt, M., \& Biavatti, V. T. (2015). Contribuições do Trabalho de Conclusão de Curso e do Estágio Curricular para a aprendizagem: percepção dos alunos dos cursos de Ciências Contábeis. Contabilidade Vista \& Revista, 26(1).

Dias, C. M. (2011). A Realização do Trabalho de Conclusão de Curso: a perspectiva dos alunos do Curso de Pedagogia da UEL.55f. Trabalho de Conclusão de Curso (Graduação em Pedagogia) - Universidade Estadual de Londrina, Londrina.

Dias, D. S; \& Silva, M. F. (2009). Como escrever uma monografia. Rio de Janeiro: UFRJ/COPPED.

Diehl, A. A. (2004). Pesquisa em ciências sociais aplicadas: métodos e técnicas [livro eletrônico]. São Paulo: Prentice Hall.

Hora, H. R. M., Monteiro, G. T. R., \& Arica, J. (2010). Confiabilidade em questionários para qualidade: um estudo com o Coeficiente Alfa de Cronbach. Produto \& Produção, 11(2), 85-103.

Krüger, L. M., Valmorbida, S. M. I., Ensslin, L., Ensslin, S. R. \& Vicente, E. F. R. (2013) Inserção dos alunos de ciências contábeis na pesquisa científica: uma análise nas Universidades Federais do Sul do Brasil. Revista ConTexto, 13(24), 51-63.

Liston, P. J.; \& Silva, M. I. (2012) A importância da disciplina de metodologia científica da elaboração do Trabalho de Conclusão de Curso - TCC nos cursos de graduação. Revista Científica da Fecra, vol. 1, n.1, p. 1-10. 
Mascarenhas, S. A. (2012). Metodologia Científica: estudo e ensino. São Paulo: Pearson Education do Brasil.

Matthiensen, A. (2011). Uso do coeficiente Alfa de Cronbach em avaliações por questionários, documentos 48. Boa Vista: Embrapa.

Medeiros, B. C., Rocha, F., Silva, R., \& Danjour, M. F. (2015). Dificuldades do processo de orientação em trabalhos de conclusão de curso (TCC): um estudo com os docentes do curso de administração de uma instituição privada de ensino superior. Holos.

Medeiros, B. C.; Silva, G. G.; \& Novais, S. M. (2011). Dificuldades técnicas e operacionais na elaboração de trabalhos monográficos em Administração: um enfoque metodológico. Revista Interface, Natal, v. 8, n. 1, p. 70-85.

Müller, M. S.; \& Cornelsen J. M. (2003) Normas e padrões para teses, dissertações e monografias. 5. ed. atual. Londrina: Eduel.

Neves, J. M. S.; \& Russi, L. (2007). N. O TCC como ferramenta para Consolidação das Competências, Adquiridas no ensino de Tecnologia na Fatec Guaratinguetá, São Paulo. In: I Encontro de Ensino e Pesquisa em Administração e Contabilidade, 2007. Recife: ENEPQ.

Peixoto, E. P. A.; França, R. D., Andrade, E. P. A., \& Menêses, F. A. F. A. (2014) A contribuição da iniciação científica na elaboração do TCC no curso de Ciências Contábeis sob a ótica do corpo discente: uma pesquisa na IES públicas do Estado da Paraíba. In: XI Congresso USP de Iniciação Científica em Contabilidade, São Paulo.

Pessoa Junior, L. S., \& Lima, D. H. S. (2015). Pesquisa em contabilidade: investigação da percepção dos discentes do curso de ciências contábeis da Universidade Federal do Rio Grande do Norte quanto sua importância e incentivos oferecidos na graduação. Anais do Seminário de Pesquisa do CCSA/UFRN, Natal, RN, Brasil, 20.

Pinto, M. J. F. (2005) A metodologia da pesquisa científica como ferramenta na comunicação empresarial. In: $2^{2}$ Congresso Virtual de Comunicação Empresarial.

Quixadá-Viana, C. M. Q.; \& Veiga, I. P. A. (2010) O diálogo acadêmico entre orientadores e orientandos. Educação, Porto Alegre, v. 33, n. 3, p. 222-226.

(2007) Orientação acadêmica: uma relação de solidão ou de solidariedade? In: ANPED: 30ª Reunião Anual da Anped, Caxambú, Minas Gerais, 2007. Didática, n. 4.

Santos, E. A. (2011). Produção Científica: uma análise de sua contribuição na formação acadêmica e profissional dos discentes de ciências contábeis da UEFS. Trabalho de Conclusão de Curso (Graduação em Ciências Contábeis) - Universidade Estadual de Feira de Santana (UEFS), Feira de Santana.

Santos, C. K. S.; \& Leal, E. A. (2014). A iniciação científica na formação dos graduandos em ciências contábeis: um estudo em uma instituição pública do triângulo mineiro. Revista Contemporânea de Contabilidade, v. 11, n. 22, p. 25-48.

Severino, A. J. (2013) Metodologia do trabalho científico [livro eletrônico]. Cortez, 1. ed., São Paulo.

Severino, A. J. (2009) Pós-graduação e pesquisa: o processo de produção e de sistematização do conhecimento. Revista Diálogo Educacional, Curitiba, v. 9, n. 26, p. 13-27. 
Silva Júnior, S. D.; \& Costa, F. J. (2014). Mensuração e escalas de verificação: uma análise comparativa das escalas de Likert e Phrase Completion. Revista Brasileira de Pesquisas de Marketing, Opinião e Mídia, v. 15, p. 1-16.

Silva, A. C. B. D., Oliveira, E. C. D., \& Ribeiro Filho, J. F. (2005). Revista Contabilidade \& FinançasUSP: uma comparação entre os períodos 1989/2001 e 2001/2004. Revista Contabilidade \& Finanças, 16(39), 20-32.

Silva, A. P. C., Sihler, A. P., S., \& Silva, C. A. (2012). Orientação de trabalhos de conclusão de curso a distância: uma experiência fundamentada na interação. Novas Tecnologias na Educação, 10(1), 1-7.

Theóphilo, C. R.; \& Iudícibus, S. (2009). Uma análise crítico-epistemológica da produção científica em contabilidade no Brasil. Contabilidade, Gestão e Governança, v. 8, n. 2. 